Obere Extremität $2017 \cdot 12: 165-170$

DOI 10.1007/s11678-017-0415-3

Received: 16 March 2017

Accepted: 18 May 2017

Published online: 29 June 2017

(c) The Author(s) 2017. This article is an open access publication.

CrossMark

Sophia M. Hünnebeck' · Petra Magosch ${ }^{2}$ Peter Habermeyer ${ }^{2} \cdot$ Markus Loew $^{2}$. Sven Lichtenberg ${ }^{2}$

${ }^{1}$ Abteilung für Obere Extremität, Hand- und Mikrochirurgie, Immanuel Krankenhaus Berlin, Berlin, Germany

${ }^{2}$ German Joint Center Heidelberg, ATOS Clinic Heidelberg, Heidelberg, Germany

\title{
Chondral defects of the glenohumeral joint
}

\section{Long-term outcome after microfracturing of the shoulder}

\section{Finding the right treatment for a young patient with glenohumeral arthritis is still a challenge. It depends not only on the radiological findings but also on the explicit age of the patient, their occupation, activity level, duration of symptoms, comorbidities and concomitant shoulder pathology.}

\section{Introduction}

Glenohumeral arthritis is a condition that can be responsible for persistent shoulder pain and functional limitation compared to a healthy individual [7]. The occurrence of glenohumeral arthritis is less common than that of the knee or hip; however, the incidence of this pathology increases with the age of the population [5]. Accompanying the increasing rate of diagnostic tool development and subsequent detection of chondral lesions, the number of young patients diagnosed with early or even later stage osteoarthritis is growing [1].

Particularly in younger patients, diagnosing early glenohumeral arthritis is often a "diagnosis of exclusion" [1]. It has been reported that the incidence of symptomatic chondral lesions (Outerbridge grade II-IV) [16] in diagnostic arthroscopy can be up to $17 \%$ in middleaged patients with full-thickness rotator cuff tears or in active overhead athletes $[4,11]$.

In case of failure of conservative therapy, surgical treatment must be con- sidered. Various treatment options exist, such as local debridement, microfracturing, restorative techniques (autologous chondrocyte implantation, osteochondral autograft transplantation surgery), joint replacement or allografts $[1,19]$. Since the long-term outcome-especially for the procedure of microfracturing of the shoulder-is still research in progress, it is important to have alternative treatment options to shoulder arthroplasty, particularly for patients younger than 60 years.

The aim of this study was to evaluate long-term outcomes following microfracture of the shoulder joint in patients with chondral lesions of the glenohumeral joint, by determining the prevalence of early stages of osteoarthritis during the follow-up period.

\section{Materials and methods}

\section{Study design, patients}

Inclusion criteria were: chondral defects of the humeral head, glenoid or both, which had been treated with arthroscopic microfracture. Exclusion criteria included history of glenohumeral instability, large rotator cuff tears, and fractures or systemic inflammatory diseases of the joint. See 0 Fig. 1 for the patient numbers at each stage. Any kind of shoulder arthroplasty after microfracture of the shoulder was defined as an endpoint of the study; these patients were included in the results according to an intention-to-treat analysis. Of the included patients, 4 were not able to present personally and the questionnaires were verbally completed by telephone. The remaining 23 patients received a clinical examination and $\mathrm{x}$-ray and MRI of the shoulder. ConstantMurley Score (CMS), Disabilities of the Arm, Shoulder and Hand (DASH) Score and an additional questionnaire for subjective evaluation of the treated shoulder were obtained. All patients signed written consent to take part in this study. Included were 17 male (53\%) and 15 female $(47 \%)$ patients with an average age of 56 years (37-74). Regarding treatment, 32 shoulders were treated with microfracturing; 11 left shoulders (34\%) and 21 right $(66 \%)$ shoulders, of which the dominant shoulder was treated in 18 cases $(56 \%)$. A minor trauma in the past was reported by 9 patients (28\%) and 23 patients $(72 \%)$ had no history of any trauma. Regarding previous surgery, 5 patients $(16 \%)$ had been operated on once before the treatment and 1 patient had already been operated upon twice. Intraoperatively, 31 patients presented with a chondral lesion grade IV according to Outerbridge (subchondral bone) and 1 patient presented with grade III (fissuring of the cartilage) [9]. The initial indication for surgery was constant shoulder pain without satisfying effects of conservative treatment. In those cases without preoperative signs of osteoarthrosis in imaging, chondral le- 


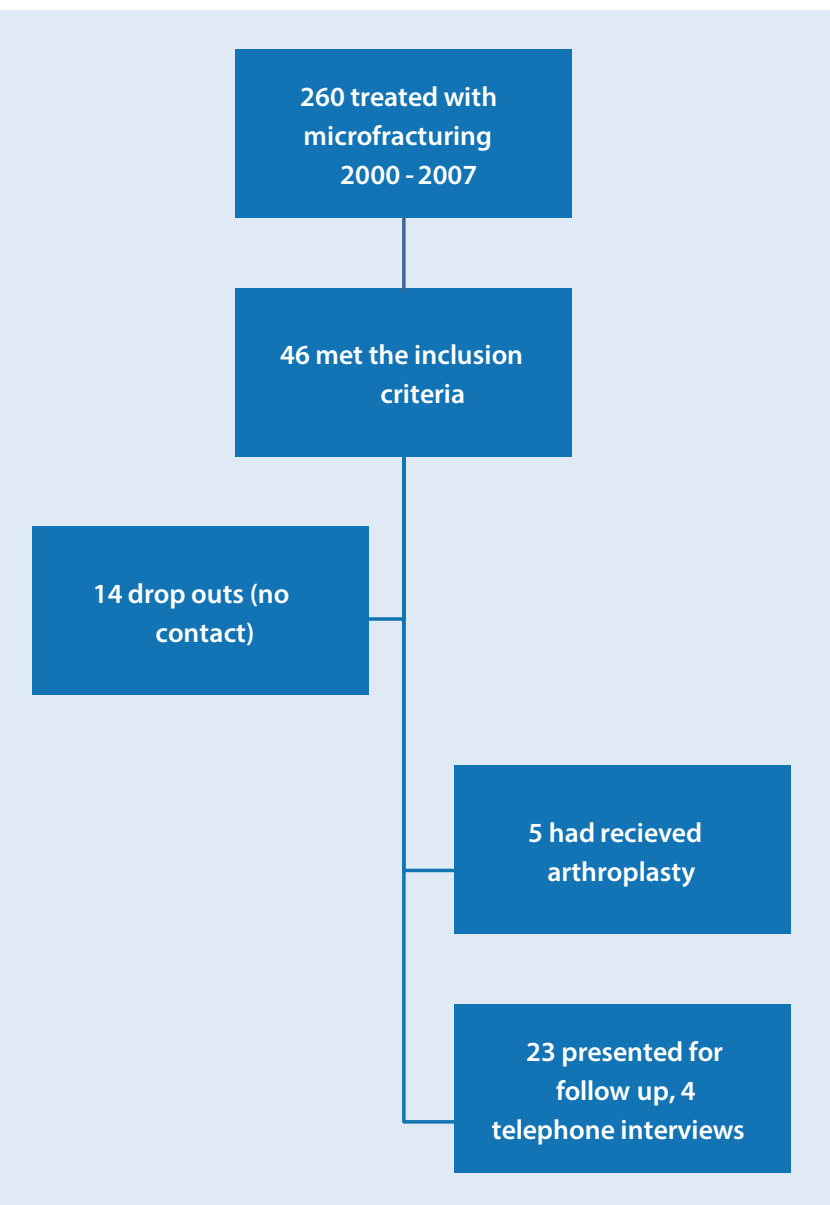

Fig. 1 Flowchart describing the patient numbers at each stage

sions were suspected but first diagnosed during arthroscopy.

In total, 30 humeral lesions and 14 glenoid lesions were treated with microfracture. Of the chondral lesions, 23 (72\%) were bipolar lesions, but only in 12 cases (38\%) was bipolar microfracturing necessary. The bipolar lesions treated were located at the centre of the humeral head and glenoid, and their sizes were big enough to locate at least $2-3 \mathrm{mi}$ crofracture spots. Since the sizes of the lesions were only documented in half of the cases and in varying descriptions, they were not taken into consideration. Accompanying this treatment, 13 patients $(41 \%)$ received a subacromial decompression, $5(16 \%)$ a resection of the AC joint, 6 (19\%) a tenotomy of the long head of the biceps tendon, $1(3 \%)$ a tenodesis of the long head of biceps tendon and 2 patients (6\%) received a SLAP (superior labral tear anterior to posterior) repair. These treatments were performed according to preoperative clinical symptoms.

\section{Surgical techniques and rehabilitation}

The senior author performed all of the operations described here. Microfracture was performed in standard arthroscopy according to Steadman [17]. Firstly, the lesions were debrided (see • Fig. 2), and as many perforations as possible were then set with a curved awl, at a distance of 3-4 mm apart, until light bleeding occurred. All patients received a standardized physiotherapy program with early functional physiotherapy in a painadapted range of motion. Continuous Passive Motion (CPM) was not used.

\section{Radiological evaluation}

Patients received $\mathrm{x}$-ray preoperatively and at the time of follow-up (anteroposterior, outlet and axillary views). For

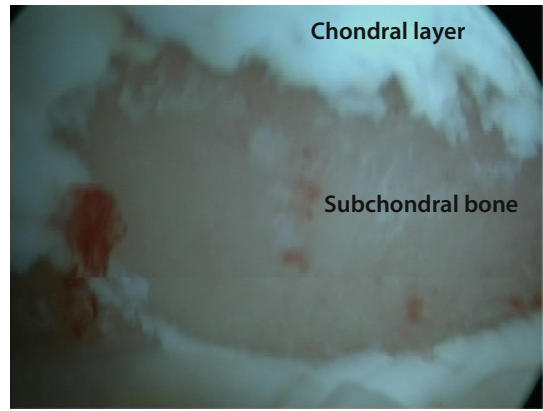

Fig. $2 \Delta$ Intraoperative findings of a chondral lesion stage IV according to Outerbridge. Patient in beach chair position, view from the anterior portal onto the humeral head

the retrospective analysis, preoperative radiographs were available from 31 out of 32 patients (one series was not available). The evaluation of osteoarthritis grade was classified according to the Samilson's classification [13].

MRI (open, $0.25 \mathrm{~T}$ ) was performed preoperatively and during the follow-up evaluation in order to quantify the quality of the chondral layer in the joint (data not shown). Unfortunately, the MRI results showed a large variation and variety of possible interpretations. Subsequently, the chondral layer was not sufficiently evaluable, and those images were not included in the analyses.

\section{Statistics}

SPSS 19.0 (IBM Company, Armonk, NY, USA) was used for statistical analysis. The Wilcoxon signed-rank test was used for comparison within groups and the Mann-Whitney U test for comparison between groups. The level of significance was marked at $p \leq 0.05$.

\section{Results}

The mean follow-up time was 105 months (64-147 months). The mean time until shoulder arthroplasty was required in these 5 patients was 47 months (5-79 months; three hemi and two total-shoulder arthroplasties). The results of the descriptive analysis of the 5 patients did not show any significant differences to the main group (mean age 57 versus 56 years, $p=0.896$ ). 
Obere Extremität 2017 · 12:165-170 DOI 10.1007/s11678-017-0415-3

(c) The Author(s) 2017. This article is an open access publication.

\section{S. M. Hünnebeck · P. Magosch · P. Habermeyer · M. Loew · S. Lichtenberg}

\section{Chondral defects of the glenohumeral joint. Long-term outcome after microfracturing of the shoulder}

\section{Abstract}

Introduction. An increasing number of young patients are diagnosed with chondral lesions. Minimally invasive surgical techniques are important in order to delay progression of the early stages of osteoarthritis and the need for total joint replacement.

Materials and methods. Patients $(n=32)$ who had received microfracturing of the shoulder were retrospectively enrolled, of whom 5 had received shoulder replacements after a mean time of 47 months. Of these patients, 23 completed the Disabilities of the Arm, Shoulder and Hand (DASH) and Constant-Murley Scores in addition to an additional subjective questionnaire. Patients were then clinically examined and received x-ray analysis of the operated shoulder. Data from an additional 4 patients were acquired by telephone interview.

Results. Mean follow-up was 105 months. Of the included patients, 13/27 patients reported no pain, $12 / 27$ patients moderate pain. Of these $12,6 / 27$ reported pain only at night and $3 / 27$ only during rest. Concerning the outcome of surgery, 19/27 patients were "satisfied" or "very satisfied". There was a statistically significant increase in internal rotation, but no further differences in the range of motion pre- and postoperatively. Patients without any signs of osteoarthritis before surgery showed statistically significantly better outcomes. There was a statistically significant increase in radiological signs of osteoarthrosis in pre- versus postoperative patients. Patients with bipolar lesions showed statistically significantly poorer Subjective Shoulder Value (SSV) results.

Conclusion. Even though microfracturing does not prevent radiographic progression, microfracture of the glenohumeral joint might be worth considering as part of a treatment regimen for younger patients who may not yet be treated with arthroplasty.

Keywords

Arthroscopy - Osteoarthritis - Omarthritis . Pain · Arthroplasty

\section{Knorpelschäden des Schultergelenks. Langzeiteffekte der Mikrofrakturierung}

\section{Zusammenfassung}

Hintergrund. Zunehmend werden bei jungen Patienten Knorpelläsionen diagnostiziert. Deren Therapie ist eine Herausforderung für den Behandler. Minimalinvasive Op.Methoden sind wichtig, um eine Progression zur Omarthrose zu verzögern und einen frühen Gelenkersatz zu vermeiden. Material und Methoden. Retrospektiv wurden 32 Patienten, bei denen eine Mikrofrakturierung erfolgt war, in die Studie eingeschlossen. Nach im Mittel 47 Monaten hatten 5 davon einen Gelenkersatz erhalten. Mittels DASH und Constant-Murley-Score sowie subjektiver Fragebögen, klinischer Untersuchung und Röntgenbild wurden 23 Patienten nachuntersucht. Bei weiteren
4 Patienten wurden die Daten der Fragebögen telefonisch erfragt.

Ergebnisse. Das durchschnittliche Follow-up lag bei 105 Monaten. Von 27 Patienten waren 13 schmerzfrei; 12 berichteten über moderate Schmerzen, davon 6 über Nacht- und 3 über Ruheschmerz. Mit dem Ergebnis sehr zufrieden oder zufrieden waren 19 Patienten. Die Innenrotation verbesserte sich statistisch signifikant im Vergleich zu vor der Op., darüber hinaus ergaben sich keine Änderungen des Bewegungsumfangs. Patienten, die zum Zeitpunkt der Op. keinerlei Zeichen der Arthrose im Röntgenbild aufwiesen, erreichten bessere Ergebnisse. Insgesamt war jedoch eine statistisch signifikante Zunahme der Omarthrose im Röntgenbild über die Zeit des Follow-up zu verzeichnen. Patienten mit intraoperativ bipolaren Läsionen wiesen im Subjective Shoulder Value (SSV) statistisch signifikant schlechtere Ergebnisse auf. Schlussfolgerung. Die Mikrofrakturierung des Schultergelenks bei lokalisierten Knorpelschäden verhindert eine radiologische Progression der Omarthrose nicht, dennoch ist die Op.-Technik als Teil einer multimodalen Therapie zu erwägen, um weitere, invasivere Therapieoptionen hinauszuzögern.

Schlüsselwörter

Arthroskopie - Arthritis - Omarthrose . Schmerz $\cdot$ Arthroplastik

\section{Clinical results}

No pain at all in the operated shoulder was reported by 13 patients $(41 \%)$ at the time of follow-up; 12 (38\%) patients experienced moderate pain at a higher activity level and 7 (22\%) during normal motions of the shoulder joint. Pain at night was still experienced by 6 (19\%) patients and 3 (9\%) experienced pain at rest. Furthermore, the patients who experienced pain stated that this was only from time to time, and always to a moderate and bearable degree. At the time of follow-up, 19 patients (59\%) were sat- isfied or very satisfied with the outcome of the intervention.

The mean ranges of motion of the affected shoulders are documented in - Table 1. There was no statistically significant difference in the ability to elevate, abduct or rotate the shoulder externally in the comparison between the preoperative situation and the time of follow-up. Only the internal rotation increased to a statistically significant degree from the height of the iliosacral joint to L1 ( $p=$ 0.033). Regarding the CMS and DASH Score, there was no statistically significant difference between the operated and the healthy shoulder at the time of follow-up. Detailed findings are reported in - Table 2. There were no statistically significant differences between the shoulders for: overall CMS $(p=0.462)$, relative CMS $(p=0.896)$, SSV $(p=0.586)$, pain level $(p=0.721)$ and DASH Score $(p=$ 0.097).

In order to evaluate the influence of preoperative signs of osteoarthritis before the treatment, patients were divided into two groups with or without preoperative radiological signs of osteoarthritis. There was no significant difference concerning the distribution of age, trauma in 


\section{Original Contribution}

Table 1 Results in the range of motion of the operated shoulder pre- and postoperatively

\begin{tabular}{|c|c|c|c|c|}
\hline & Elevation & Abduction & IRO & ERO \\
\hline Preoperative & $140^{\circ} \pm 53^{\circ}$ & $144^{\circ} \pm 57^{\circ}$ & $I S J \pm 32^{\circ}$ & $45^{\circ} \pm 22^{\circ}$ \\
\hline Postoperative & $153^{\circ} \pm 49^{\circ}$ & $168^{\circ} \pm 8^{\circ}$ & $\mathrm{L} 1 \pm 11^{\circ}$ & $49^{\circ} \pm 21^{\circ}$ \\
\hline
\end{tabular}

Table 2 ResultsinConstant-Murley Score(CMS), subjective shouldervalue(SSV) and Disabilities of the Arm, Shoulder and Hand (DASH) Score of the operated and non-operated shoulder at the time of follow-up examination

\begin{tabular}{lll} 
& Operated shoulder & Non-operated shoulder \\
\hline CMS & $74 \pm 26$ points & $75 \pm 28$ points \\
Relative CMS & $95 \pm 14 \%$ & $95 \pm 31 \%$ \\
Pain value & $12.9 \pm 3$ points & $13 \pm 3.7$ points \\
SSV & $86 \pm 13 \%$ & $88 \pm 19 \%$ \\
DASH & 12 points & 8 points
\end{tabular}

Table 3 Comparison between the groups with or without preoperative osteoarthritis (OA)

\begin{tabular}{|c|c|c|c|}
\hline & Preop. OA & Preop. no signs & Significance \\
\hline Mean age (years) & 56 & 55 & $P=0.976$ \\
\hline Trauma preop (n) & 4 & 2 & $P=0.449$ \\
\hline CMS & $76 \pm 14$ points & $72 \pm 35$ points & $P=0.413$ \\
\hline Relative CMS & $89 \pm 15 \%$ & $102 \pm 8 \%$ & $P=0.019^{*}$ \\
\hline DASH & 15 points & 9 points & $P=0.037^{*}$ \\
\hline Pain during activity & $8 / 11$ & $1 / 11$ & $P=0.007^{*}$ \\
\hline Satisfaction & 3 very/6 satisfied/3 less & 10 very/2 satisfied & $P=0.016^{*}$ \\
\hline \multicolumn{4}{|c|}{$\begin{array}{l}\text { CMS Constant-Murley Score, SSV subjective shoulder value, DASH Disabilities of the Arm, Shoulde } \\
\text { and Hand. Preop preoperative } \\
{ }^{*}=P<0.05\end{array}$} \\
\hline
\end{tabular}

\begin{tabular}{l|l|l|l|l|l|l} 
Table 4 & \multicolumn{7}{l}{ Radiological results of all patients } \\
& $\begin{array}{l}\text { X-ray } \\
\text { Samil- } \\
\text { Son 0 }\end{array}$ & $\begin{array}{l}\text { X-ray } \\
\text { Samil- } \\
\text { son I }\end{array}$ & $\begin{array}{l}\text { X-ray } \\
\text { Samil- } \\
\text { son II }\end{array}$ & $\begin{array}{l}\text { X-ray } \\
\text { Samil- } \\
\text { son III }\end{array}$ & $\begin{array}{l}\text { Gleno- } \\
\text { humeral } \\
\text { distance }\end{array}$ & $\begin{array}{l}\text { Acromio- } \\
\text { humeral } \\
\text { distance }\end{array}$ \\
\hline Preop & $N=14$ & $N=10$ & $N=5$ & $N=2$ & $2.6 \pm 2.3 \mathrm{~mm}$ & $6.5 \pm 5.2 \mathrm{~mm}$ \\
\hline $\begin{array}{l}\text { Follow-up } \\
\text { Follow-up } \\
\text { patients preop } \\
\text { Samilson 0 }\end{array}$ & $N=5$ & $N=8$ & $N=8$ & $N=2$ & $2.4 \pm 1.9 \mathrm{~mm}$ & $7.4 \pm 2.9 \mathrm{~mm}$ \\
\hline
\end{tabular}

the anamnesis and overall CMS. Significant differences were observed in relative CMS, DASH Score, pain during activity and satisfaction (see 0 Table 3 and

\section{- Fig. 3).}

Furthermore, data were analysed according to the question of whether patients with radiologic progression of osteoarthritis had a different outcome to those without progression in the $\mathrm{x}$-ray (mean age of 57 vs. 54 years, $p=0.494$ ). In CMS and DASH Score, there were no statistically significant differences between the groups (overall CMS $83 \pm 12$ vs.
$63 \pm 35$ points, $p=0.121$; relative CMS $98 \pm 13 \%$ vs. $91 \pm 14 \%, p=0.242$; DASH Score $13 \pm 16$ vs. $13 \pm 11$ points, $p=$ 0.552 ). A previous shoulder injury also had no statistically significant influence on the outcome. The distribution of age was again similar in those groups (mean age of 53 years with a previous injury, 57 years without, $p=0.233$ ). The overall CMS in the group with a previous injury was $78 \pm 19$ points, the relative CMS $89 \pm$ $17 \%$ and DASH Score $7 \pm 3$, versus an overall CMS of $73 \pm 29$ points $(p=0.674)$, a relative CMS of $97 \pm 12 \%(p=0.223)$ and a DASH Score of $10 \pm 14$ points $(p=$ 0.392 ) in the group without a previous injury.

Patients with bipolar lesions showed statistically significantly lower results in the Subjective Shoulder Value (SSV; mean SSV $=80.6$ in the group with bipolar lesions and SSV $=94.7$ in patients with unipolar lesions, $p=0.039$ ). There were 19 patients with bipolar lesions (mean age $54 \pm 9$ years) and 8 patients with unipolar lesions (mean age $61 \pm 8$ years; seven glenoidal and one humeral unipolar lesion).

\section{Radiological results}

The results of the $\mathrm{x}$-ray evaluation are shown in - Table 4. Progression of osteoarthritis was suffered by 13 patients (57\%), which was found to be statistically significant $(p=0.002)$.

In the separated groups, with and without preoperative signs of osteoarthritis in the $\mathrm{x}$-rays, patients with preoperative signs of osteoarthritis had a progression to higher stages according to Samilson than those without preoperative signs $(p=0.013)$. Those patients without preoperative signs of osteoarthritis in initial $x$-rays were significantly more content with the result $(p=0.003)$ and reported less pain during activity $(p=$ 0.031 ).

\section{Discussion}

After a mean follow-up time of 105 months, 13/27 patients reported no pain, $12 / 27$ patients moderate pain. Of these $12,6 / 27$ reported pain only at night and $3 / 27$ only during rest. Regarding the outcome of surgery, 19/27 patients indicated that they were "satisfied" or "very satisfied". There were no differences in the ranges of motion pre- and postoperatively, except for a statistically significant increase in internal rotation. Patients without any signs of osteoarthritis before the operation showed statistically significantly better outcomes. There was a statistically significant increase in radiological signs of osteoarthrosis in preversus postoperative patients. Patients with bipolar lesions showed statistically significantly poorer SSV results. 


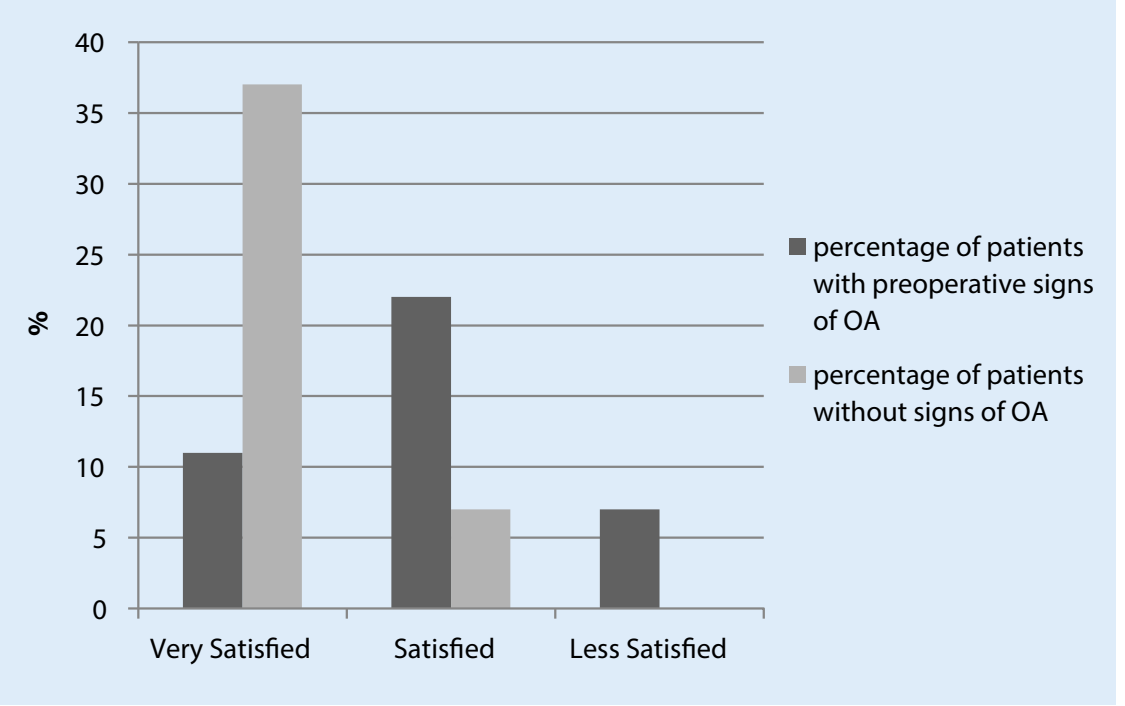

Fig. $3 \Delta$ Satisfaction of patients with and without any preoperative signs of osteoarthrosis $(O A)$

Microfracturing has been described as a treatment option for chondral defects in various studies. The procedure for microfracture in the knee was first published in 1999 [3, 16-18], with promising long-term results observed in the knee and talus $[6,10,12]$. However, to the best of our knowledge, only a few studies deal with this procedure in the shoulder, with a notable lack of studies investigating the long-term effects of microfracture in this joint. There have been studies with promising results but very low numbers of patients. A follow-up on 5 patients treated with a combination of microfracture and periostal flap (because of a chondral defect of the humeral head) revealed a good clinical outcome and pain reduction after 26 months [14]. Another cohort of 8 patients treated with microfracture of the shoulder showed a significant increase in CMS after 15 months, as did another group of 16 patients retrospectively reviewed after 28 months $[2,15]$.

Comparing our results to these previous studies, this study, to the best of our knowledge, describes the longest duration of follow-up on the largest cohort of patients that has been published to date. Here, 5 patients underwent total or partial shoulder arthroplasty after a mean time of 47 months after microfracture, which was still a subjective benefit for younger patients. According to the results of earlier studies, we also noted that even though the clinical outcome after microfracture should be informed of the higher postoperative risk of ongoing symptoms.

It should be noted that in this study, minor side pathologies other than the microfracture were treated during the arthroscopy. This has been reported in many of the previous studies. There is no doubt that treatment of side pathologies concurrently with the microfracture can have a major impact on the outcome after these surgeries. However, there are few cases with clearly isolated chondral lesions without any other pathology in the glenohumeral joint. Leaving an obvious pathology in the joint untreated influences the outcome after microfracture to at least the same degree. Furthermore, it is not in the patient's best interest to leave a pathology untreated with the knowledge that this could lead to further pain and dysfunction. Ultimately we have to accept that microfracture is only one part of a complex treatment of the degenerated glenohumeral joint.

\section{Practical conclusion} the main indications for further treatments such as total or partial shoulder arthroplasty. Therefore, the main goal of any treatment option prior to these interventions should focus on maintaining a bearable status of the shoulder joint for as long as possible. A treatment like microfracturing seems to be a good option to delay the onset of symptoms and maintain shoulder function.

For prediction of the outcome of microfracturing, it should be taken into consideration that bipolar lesions seem to result in worse postoperative results. A study performed on 31 shoulders revealed the best postoperative outcome in patients with isolated lesions compared to a group with bipolar lesions after 47 months [8]. In our study, patients with unipolar lesions achieved statistically significantly better SSV results compared to patients also having bipolar lesions. No statistically significant differences in the groups with bipolar and unipolar lesions were seen for the range of motion and subjective pain and functionality questions. Nevertheless, unipolar lesions seem to represent the best indication for the treatment and patients with bipolar lesions
Microfracturing of the glenohumeral joint does not stop the natural process and progression of osteoarthrosis, but the clinical outcome is still satisfying for the patients. The patients studied here reported only few symptoms, most notably less pain for 5 years or more. The radiological findings show that microfracturing does not prevent radiographic progression of osteoarthritis. In cases of early chondral lesion without any radiological signs of osteoarthritis, the clinical outcome was best. Patients with bipolar lesions have lower SSV scores. According to the results presented, arthroscopic treatment with microfracture should be taken into consideration as part of a complex treatment of the degenerated glenohumeral joint. 


\section{Corresponding address}

Dr. med. S. M. Hünnebeck
Abteilung für Obere
Extremität, Hand- und
Mikrochirurgie, Immanuel
Krankenhaus Berlin
Königstraße 63, 14109 Berlin,
Germany
Sophiahuennebeck@
gmail.com

Acknowledgements. The authors thank Dr. Roland Ventura, Samantha Chapman and Dipl-Psych. Claas Güthoff for scientific advice

\section{Compliance with ethical guidelines}

Conflict of interest. S.M. Hünnebeck, P. Magosch, P. Habermeyer, M. Loew and S. Lichtenberg declare that they have no competing interests.

All procedures performed in studies involving human participants were in accordance with the ethical standards of the institutional and/or national research committee and with the 1964 Helsinki declaration and its later amendments or comparable ethical standards. Informed consent was obtained from all individual participants included in the study.

Open Access. This article is distributed under the terms of the Creative Commons Attribution 4.0 International License (http://creativecommons.org/licenses/by/ 4.0/), which permits unrestricted use, distribution, and reproduction in any medium, provided you give appropriate credit to the original author(s) and the source, provide a link to the Creative Commons license, and indicate if changes were made

\section{References}

1. Bhatia S, Hsu A, Lin EC et al (2012) Surgical treatment options for the young and active middle-aged patient with glenohumeral arthritis. Adv Orthop 2012:846843

2. Frank RM, Van Thiel GS, Slabaugh MA et al (2010) Clinical outcomes after microfracture of the glenohumeral joint. Am J Sports Med 38:772-781

3. Frisbie DD, Trotter GW, Powers BE et al (1999) Arthroscopic subchondral bone plate microfracture technique augments healing of large chondral defects in the radial carpal bone and medial femoral condyle of horses. Vet Surg 28:242-255

4. Gartsman GM, Taverna E (1997) The incidence of glenohumeral joint abnormalities associated with full-thickness, reparable rotator cuff tears. Arthroscopy 13:450-455

5. lanotti JP, Williams GR (1999) Disorders of the shoulder: Diagnosis and management. Lippincott Williams \& Wilkins, Philadelphia

6. Kuni B, Schmitt H, Chloridis D et al (2012) Clinical and MRI results after microfracture of osteochondral lesions of the talus. Arch Orthop Trauma Surg 132:1765-1771

7. Matsen FA 3rd, Ziegler DW, Debartolo SE (1995) Patient self-assessment of health status and function in glenohumeral degenerative joint disease. J Shoulder Elbow Surg 4:345-351

8. Millett PJ, Huffard BH, Horan MP et al (2009) Outcomes of full-thickness articular cartilage injuries of the shoulder treated with microfracture. Arthroscopy 25:856-863

9. Outerbridge RE (1961) The etiology of chondromalacia patellae. J Bone Joint Surg Br 43B:752-757

10. Ozturk A, Ozdemir MR, Ozkan Y (2006) Osteochondral autografting (mosaicplasty) in grade IV cartilage defects in the knee joint: 2- to 7-year results. Int Orthop 30:200-204

11. PaleyKJ, JobeFW, PinkMMetal (2000) Arthroscopic findings in the overhand throwing athlete: Evidence for posterior internal impingement of the rotator cuff. Arthroscopy 16:35-40

12. Passler HH (2000) Microfracture for treatment of cartilage detects. ZentralbI Chir 125:500-504

13. Samilson RL, Prieto V (1983) Dislocation arthropathy of the shoulder. J Bone Joint Surg Am 65:456-460

14. Siebold R, Lichtenberg S, Habermeyer P (2003) Combination of microfracture and periostal-flap for the treatment of focal full thickness articular cartilage lesions of the shoulder: A prospective study. Knee Surg Sports Traumatol Arthrosc 11:183-189

15. Snow M, Funk L (2008) Microfracture of chondral lesions of the glenohumeral joint. Int J Shoulder Surg 2:72-76

16. Steadman JR, Briggs KK, Rodrigo JJ et al (2003) Outcomes of microfracture for traumatic chondra defects of the knee: average 11-year follow-up. Arthroscopy 19:477-484

17. Steadman JR, Rodkey WG, Briggs KK et al (1999) The microfracture technic in the management of complete cartilage defects in the knee joint. Orthopäde 28:26-32

18. Steadman JR, Rodkey WG, Rodrigo JJ (2001) Microfracture: surgical technique and rehabilitation to treat chondral defects. Clin Orthop Relat Res (391 Suppl):362-369

19. Van Der Meijden OA, Gaskill TR, Millett PJ (2012) Glenohumeral joint preservation: a review of management options for young, active patients with osteoarthritis. Adv Orthop 2012:160923 